\title{
Trasplante renal doble (TRD) de donantes añosos
}

\author{
Pedro Méndez-Chacón ${ }^{1,2}$, Armando Vidalón ${ }^{1,2}$, Mario Medina ${ }^{2}$, \\ Miguel Camacho ${ }^{2}$, José Somocurcio ${ }^{3}$
}

Resumen

Palabras clave

\begin{abstract}
Objetivo: Utilizar ambos riñones del donante añoso en un mismo receptor y resaltar la importancia de la histología renal como método seleccionador. Materiales y Métodos: Se evalúa la elección y seguimiento de 11 pacientes quienes recibieron riñones dobles de donantes cadavéricos añosos. La creatinina sérica promedio de los 11 donantes fue de 1,3 mg\%, cursando con edades promedio de 63 años (56 a 73) y de 53 años en los receptores. Ambos riñones fueron sometidos a biopsia en cuña por congelación. La cuantificación del tejido dañado se basó en metodología ya definida. Riñones con lesiones microscópicas moderadas (puntaje 4 a 6/12) fueron seleccionados para trasplante renal doble. Estos fueron implantados extraperitonealmente en cada fosa ilíaca con anastomosis a vasos ilíacos externos y ambos uréteres por separado a la vejiga. Esteroides y micofenolato de mofetil conformaron el esquema inmunosupresor de primera línea. Resultados: Ningún receptor requirió hemodiálisis postrasplante. Nueve de los once receptores cursan con función renal aceptable a dos años promedio de seguimiento. Un receptor falleció por accidente cerebrovascular (ACV) hemorrágico a los 36 meses del trasplante con injerto funcionante y otro presentó enfermedad neoplásica a 38 meses del postimplante. Conclusiones: El trasplante renal doble de donante añoso constituye opción inédita en nuestro medio para receptores añosos. Resaltamos la histología renal como método en la elección del donante. Futuras investigaciones mostrarán si el trasplante renal doble, incrementando la masa nefronal, sirva para demorar o prevenir la disfunción crónica del injerto a largo plazo.
\end{abstract}

Trasplante de riñón; donantes de tejido; biopsia; riñón.

\section{Elderly donors double kidney transplantation (DKT)}

Abstract

Objective: To use both kidneys of an elderly donor in the same receptor and remark the importance of kidney histology as selector method. Materials and Methods: We evaluate the selection and surveillance of 11 patients who received double kidney of cadaver elderly donors. The ten donors' mean serum creatinine was $1,3 \mathrm{mg} / \mathrm{dL}$, and the mean age was 63 years old (range 56 to 73 years), the receptor's mean age 53 years. Both kidneys were examined by frozen wedge biopsy. Quantification of damaged tissue was based on defined methodology. Kidneys with moderate microscopic lesions (score 4 to 6/12) were selected for

1 Facultad de Medicina, UNMSM. Lima, Perú.

2 Servicio Nefrología. Servicio de Patología. Hospital Nacional Edgardo Rebagliati Martins. Lima, Perú. double kidney transplantation. These were implanted extraperitoneally into each iliac fossa with both separate iliac external vessels and bladder-ureters anastomosis. Steroids and mycophenolat-mophetil represented the first line immunosupresor scheme. Results: None of the receptors required post-transplantation hemodialysis. Nine of eleven receptors kept acceptable renal function in two average surveillance years. One receptor with working allograph died with hemorrhagic vascular cerebral disorder 36 months post transplantation and another developed neoplasia 38 months post transplantation. Conclusions: Elderly donor double renal transplantation is a novel option for elderly receptors in our country. We remark renal histology as a donor selection method. Further investigation will show if double renal transplantation increasing nephron mass will be useful to retard or prevent long time chronic allograph dysfunction. Keywords: Kidney transplantation; tissue donors; biopsy; kidney. 


\section{INTRODUCCIÓN}

El trasplante renal es el tratamiento de elección en los pacientes con insuficiencia renal crónica terminal. Su demanda se incrementa anualmente $30 \%$ en el país. A pesar de los intensos esfuerzos en promover la donación de órganos, el número de donantes cadavéricos permanece estacionario $\left({ }^{1-3}\right)$ ocasionando con ello tiempos de espera prolongados con incremento de la morbimortalidad en diálisis $\left({ }^{4,5}\right)$.

Diversas estrategias se plantea a fin de ampliar los criterios de selección de los donantes $\left({ }^{1,6,7}\right)$. Es así que, algunos centros de trasplante evalúan la utilización de injertos renales de donantes marginales $\left({ }^{7,8}\right)$. En concordancia con otros países, la edad promedio de los donantes cadavéricos va en ascenso $\left({ }^{1,9-11}\right)$. Este cambio en el perfil del donante revela características peculiares del injerto renal y de su evolución en el postrasplante $\left(^{1,9,12}\right)$. Los donantes añosos (mayores de 55 años de edad) con frecuencia cursan con hipertensión arterial y/o diabetes mellitus, lo que conlleva que la masa nefronal sea subóptima y su reserva funcional disminuida $(2,10,13)$. Los injertos renales procedentes de donantes añosos además son muy sensibles a cualquier noxa (isquemia, rechazo, fármacos nefrotóxicos) y poseen una capacidad de recuperación marcadamente inferior comparados con los injertos procedentes de donantes jóvenes $\left.{ }^{(2,8,9,14}\right)$.

Nuestra organización trasplantadora implementa un protocolo en el que se utiliza ambos riñones del donante añoso en un mismo receptor (trasplante renal doble - TRD), con el fin de garantizar mayor masa nefronal, previniendo así el deterioro progresivo de la función del injerto $\left({ }^{7,8,10}\right)$. Resaltamos la importancia de la histología renal en la selección de estos donantes $\left({ }^{2,14-17}\right)$ y se analiza la función del injerto y su sobrevida en los once primeros pacientes sometidos a TRD.

\section{MATERIALES Y MÉTODOS}

En agosto de 2000, se estableció el grupo de estudio del trasplante renal doble (TRD), con el objetivo de utilizar riñones subóptimos en receptores seleccionados. Antes de esa fecha, los donantes cadavéricos mayores de 55 años de edad con hipertensión arterial y/o diabetes mellitus eran descartados, ya que se presumía que podrían tener algún grado de glomeruloesclerosis.

Hoy se acepta como donante potencial aquel que presenta funcionalismo renal normal, independientemente de su edad cronológica $\left({ }^{18}\right)$.

En nuestro estudio, la creatinina sérica promedio de los once donantes añosos seleccionados fue $1,3 \mathrm{mg} \%$, cursando con edades promedio de 63 años (56 a 73) y de 53 años (40 a 64) en los receptores correspondientes. Los riñones extraídos fueron sometidos a evaluación macroscópica inicial, siendo excluidos aquellos con severa ateromatosis vascular.

Cuatro de los once donantes padecieron hipertensión arterial crónica y diabetes mellitus, mostrando además pequeñas lesiones ateromatosas en la arteria renal. Rutinariamente, y previa a la ablación, se solicitó marcadores tumorales y ecografía renal.

Se efectuó biopsias en cuña por congelación en los riñones procedentes de donantes marginales. El estudio histológico cuantificó el daño en concordancia a método semicuantitativo ya definido $\left({ }^{7,15-17}\right)$. Se evaluó la presencia y grado de glomeruloesclerosis, fibrosis intersticial, atrofia tubular y esclerosis vascular. Los riñones con lesiones microscópicas moderadas (puntaje 4 a 6/12) fueron seleccionados para TRD.

Éstos fueron implantados retroperitonealmente en cada fosa iliaca, con anastomosis a vasos ilíacos externos y los uréteres anastomosados por separado a la vejiga.

Los receptores seleccionados fueron preferentemente añosos (más de 55 años de edad) $\left({ }^{19}\right)$, por consiguiente con bajo riesgo inmunológico y cuya diferencia de peso con el donante fuera menor de $10 \%$ a favor del 
receptor. Los esteroides y el micofenolato mofetil conforman el esquema inmunosupresor de primera línea.

\section{RESULTADOS}

Ningún receptor requirió hemodiálisis en el postrasplante inmediato. La depuración de creatinina fue virtualmente idéntica a la de los correspondientes donantes pretrasplante. Dos de los once receptores presentaron episodios de rechazo agudo, requiriendo uso de ciclosporina como terapia de rescate.

Ocho de los once receptores cursaron con satisfactoria función del injerto renal a mediano y largo plazo (2 a 42 meses). Un receptor falleció por ACV hemorrágico a los 36 meses del transplante y con injerto funcionante; otro receptor presentó enfermedad neoplásica a 38 meses del implante; un tercero reingresó a hemodiálisis por disfunción crónica del injerto a 6 meses del implante y un cuarto paciente falleció por tuberculosis sistémica a los 23 meses postrasplante (Tablas 1 y 2 ).
Tabla 1. Biopsia del riñón del donante pretrasplante.

\begin{tabular}{llccccc}
\hline \multirow{2}{*}{ Paciente } & \multicolumn{5}{c}{ Riñón } \\
\cline { 2 - 7 } 1. RHA & Lado & $\begin{array}{c}\text { EGG } \\
(0-3)\end{array}$ & $\begin{array}{c}\text { AT } \\
(0-3)\end{array}$ & $\begin{array}{c}\text { FI } \\
(0-3)\end{array}$ & $\begin{array}{c}\text { EA } \\
(0-3)\end{array}$ & $\begin{array}{c}\text { Puntaje } \\
\text { final }\end{array}$ \\
\hline \multirow{2}{*}{ 2. MOJ } & Derecho & 1 & 1 & 1 & 1 & 4 \\
& Izquierdo & 1 & 1 & 1 & 1 & 4 \\
3. PGT & Derecho & 0 & 1 & 0 & 0 & 1 \\
& Izquierdo & 1 & 1 & 0 & 1 & 3 \\
4. ECI & Derecho & 0 & 1 & 1 & 2 & 4 \\
& Izquierdo & 0 & 1 & 1 & 2 & 4 \\
5. RMM & Derecho & 0 & 1 & 1 & 2 & 4 \\
& Izquierdo & 2 & 1 & 1 & 0 & 4 \\
6. CCA & Derecho & 1 & 1 & 0 & 1 & 3 \\
& Izquierdo & 1 & 1 & 0 & 1 & 3 \\
7. LMJ & Derecho & 1 & 1 & 1 & 1 & 4 \\
& Izquierdo & 0 & 1 & 1 & 1 & 3 \\
8. NGG & Derecho & 0 & 1 & 0 & 1 & 2 \\
& Izquierdo & 1 & 1 & 1 & 1 & 4 \\
9. EMJ & Derecho & 1 & 2 & 1 & 1 & 5 \\
& Izquierdo & 0 & 1 & 1 & 1 & 3 \\
& Derecho & 1 & 1 & 1 & 1 & 4 \\
10. MPA & Izquierdo & 0 & 1 & 1 & 1 & 3 \\
& Derecho & 0 & 1 & 0 & 1 & 2 \\
11. POJ & Izquierdo & 0 & 1 & 0 & 2 & 3 \\
& Derecho & 1 & 2 & 1 & 1 & 5 \\
& Izquierdo & 1 & 2 & 1 & 2 & 6 \\
\hline
\end{tabular}

EGG: Esclerosis glomerular global.

AT: Atrofia tubular. FI: Fibrosis intersticial.

EA: Estrechamiento arteriolar.

Tabla 2. Características del donante y receptor del TRD.

\begin{tabular}{|c|c|c|c|c|c|c|c|c|c|}
\hline \multicolumn{4}{|c|}{ Donante } & \multicolumn{6}{|c|}{ Receptor } \\
\hline & Paciente & Edad & $\overline{\text { Sexo }}$ & Paciente & Edad & Sexo & $\begin{array}{c}\text { Fecha } \\
\text { trasplante }\end{array}$ & $\begin{array}{c}\text { Terapia } \\
\text { inmunosupresora }\end{array}$ & $\begin{array}{c}\text { Resultados } \\
\text { Creatin(meses) }\end{array}$ \\
\hline 1. & RHA & 71 & M & $\mathrm{UCH}$ & 64 & M & 16.08 .00 & $\mathrm{PDN}-\mathrm{MMF}$ & $1,4(38)^{a}$ \\
\hline 2. & MOJ & 59 & M & CTJ & 53 & M & 29.03.01 & CyA - PDN - MMF & $1,9(52)$ \\
\hline 3. & PGT & 73 & M & LAJ & 64 & M & 05.04 .01 & PDN - MMF & $1,8(23)^{b}$ \\
\hline 4. & ECI & 57 & M & QVA & 52 & M & 18.07.01 & PDN - MMF & $2,3(36)^{c}$ \\
\hline 5. & RMM & 65 & $\mathrm{~F}$ & WBC & 41 & $\mathrm{~F}$ & 08.08 .01 & PDN - MMF & $1,3(46)$ \\
\hline 6. & CCA & 66 & M & ВТМ & 40 & F & 29.11 .01 & $\mathrm{PDN}-\mathrm{MMF}$ & $1,1(43)$ \\
\hline 7. & LMJ & 63 & M & TCHA & 52 & $\mathrm{~F}$ & 14.08 .02 & CyA - PDN - MMF & $1,1(37)$ \\
\hline 8. & NGG & 69 & $\mathrm{~F}$ & $\mathrm{LBH}$ & 56 & M & 02.01 .03 & PDN - MMF & $1,5(30)$ \\
\hline 9. & EMJ & 61 & $\mathrm{~F}$ & SBI & 53 & $\mathrm{~F}$ & 18.10 .03 & $\mathrm{PDN}-\mathrm{MMF}$ & $6,0(6)^{d}$ \\
\hline 10. & - MPA & 56 & F & SAL & 49 & M & 08.08 .04 & $\mathrm{PDN}-\mathrm{MMF}$ & $1,3(12)$ \\
\hline 11. & POJ & 58 & M & PON & 57 & M & 14.05 .05 & PDN - MMF & $1,1(3)$ \\
\hline
\end{tabular}

Complicaciones:

a: Neoplasia maligna

b: Tuberculosis sistémica

c: ACV hemorrágico masivo

d: Disfunción crónica del injerto
PDN: Prednisona

MMF: Micofenolato mofetil

CyA: Ciclosporina A. 


\section{DISCUSIÓN}

De 1992 a 2000, el número de pacientes que esperan trasplante renal en el Perú se ha triplicado, mientras que el número de trasplantes se mantiene estacionario. Durante ese mismo período, al igual que en otros países, se constata variación en la edad cronológica de los pacientes en diálisis y de los donantes de órganos cadavéricos $\left({ }^{3,4}\right)$.

Los pacientes en diálisis revelan marcado envejecimiento como población. Es así que 87 de los 207 (42\%) pacientes en nuestra lista de espera eran mayores de 50 años (febrero 2000). En EEUU, la edad promedio de pacientes que inician diálisis es de 62 años y cerca de $50 \%$ de los pacientes en diálisis son mayores de 65 años $\left({ }^{20}\right)$.

Hemos observado que los donantes añosos se han incrementado de 6\% (1993) a 37\% (2001), según nuestro registro.

En los centros trasplantadores, los donantes añosos actualmente constituyen la mayor fuente potencial de órganos cadavéricos $(2,5,6,8,13,15,21)$ y el estudio histológico renal es fundamental como método seleccionador para su uso en trasplante renal $\left({ }^{22,23}\right)$. Gracias a esa política de realizar biopsias renales $\left({ }^{10}\right)$, el Banco de Órganos de Nueva Inglaterra logró rescatar 93 riñones de donantes mayores de 60 años de edad entre 1993 y 1994.

Los reportes señalan resultados pobres en los trasplantes renales simples procedentes de donantes añosos, alta tasa de función demorada del injerto (40 a $80 \%$ ) y baja sobrevida a largo plazo $\left({ }^{16}\right)$. Las investigaciones al respecto, han revelado que el peso y volumen de los riñones disminuyen entre 20 y $30 \%$ a partir de los 40 a 90 años de edad $\left({ }^{16}\right)$, la esclerosis glomerular se incrementa hasta un $30 \%$ del universo glomerular $\left({ }^{13}\right)$, demostrándose asimismo, en otro estudio, que la masa nefronal trasplantada es determinante en la sobrevida del injerto renal $\left({ }^{24}\right)$. Se describe también en los riñones añosos alteraciones en la vasculatura y membrana basal glomerular, que influyen en la disminución de la tasa de filtración glomerular renal $\left({ }^{13}\right)$. Son cambios fisiológicos más que patológicos $\left({ }^{19}\right)$ y que inciden a corto y mediano plazo la sobrevida del injerto renal $\left({ }^{13}\right)$,

Se realiza un esfuerzo continuo en los centros de trasplante por acortar la disparidad entre la oferta y demanda de órganos, empleándose para ello diversas estrategias a fin de aceptar los órganos de donantes añosos $(2,8,25)$. En un reporte reciente (año 2003), 70 centros de trasplantes de EEUU adoptaron la política de realizar TRD ${ }^{(6)}$. El incremento de nefronas alcanzado con este procedimiento doble, garantiza buena reserva funcional y resistencia a los insultos inmunológicos y no inmunológicos $\left({ }^{2,7,25}\right)$. Ambos riñones son sometidos a biopsia en cuña a fin de precisar la cuantificación del tejido dañado, aplicando una metodología ya establecida $\left({ }^{15-17,26,27}\right)$. Un puntaje de lesiones moderadas de 4 a 6/12 fue adoptado para el TRD; puntaje menor de 3 fue considerado adecuado para realizar dos trasplantes renales simples y aquellos riñones añosos con puntaje de 7 ó más fueron descartados.

En agosto 2000, nuestro país realizó el primer TRD en paciente de 64 años con riñones procedentes de un donante de 71 años, con función renal aceptable y cuyo estudio histológico reveló lesiones moderadas en cada riñón (puntaje 4/12) (Tabla 1).

A la fecha del presente reporte, el HNERM ha realizado once TRD (Tabla 2). Ningún receptor requirió de hemodiálisis en el postrasplante inmediato, coincidiendo con lo observado en el Registro de EE.UU. de pacientes con TRD, que señala disminución ostensible de casos con función demorada del injerto $\left(^{6}\right)$.

Nueve de los once receptores cursan con función renal aceptable al año de seguimiento. Un receptor falleció por ACV hemorrágico a los 36 meses del postrasplante y con injerto funcionante, coincidiendo con los reportes que 
sindican dicha causa como la más frecuente de muerte en los pacientes añosos $\left({ }^{28}\right)$. El otro receptor presentó enfermedad neoplásica a 38 meses del postrasplante, coincidiendo con lo reportado que señala mayor vulnerabilidad del receptor añoso a las neoplasias por la inmunosupresión $\left({ }^{18,29,30}\right)$. Un tercer receptor reingresó a hemodiálisis por disfunción crónica del injerto y un cuarto receptor falleció por tuberculosis sistémica a los 23 meses del postimplante con injerto funcionante. Reciente publicación demuestra que el TRD cursa con sobrevida ligeramente inferior si se compara con el trasplante renal simple de donante idóneo. El TRD tiene 7\% de sobrevida del injerto inferior al año y si la curva de sobrevida continúa, ésta diverge en $15 \%$ a tres años de seguimiento $\left(^{6}\right)$.

Los reportes defienden el concepto de usar donantes añosos en receptores añosos $\left({ }^{3,21,23,31}\right)$. La sobrevida del receptor añoso/donante añoso es mejor que si permanece en diálisis $\left({ }^{4,5}\right)$. El concepto de utilizar riñones de donantes mayores de 80 años de edad está siendo cada vez más explorado $\left({ }^{20}\right)$. La utilización de riñones de los abuelos probablemente se incremente en el futuro, siempre que tengan funcionalismo renal aceptable.

Estudios recientes reportan que la mejor sobrevida del injerto ocurre cuando los riñones añosos son utilizados en receptores añosos (mayores de 65 años de edad) que en receptores jóvenes $\left({ }^{8,13,32}\right)$. Los receptores añosos, por sus características biológicas, tienen menor riesgo inmunológico $\left({ }^{18}\right)$, presentan consiguientemente menor incidencia de rechazo agudo del injerto renal $(3,4,18,29,33)$. Tratándose de pacientes de bajo riesgo inmunológico, una terapia inmunosupresora menos agresiva podría ser suficiente para prevenir el rechazo agudo $\left({ }^{18,28}\right)$ y a su vez también disminuir el riesgo de infecciones en el receptor añoso $\left({ }^{28,29}\right)$.

Nosotros utilizamos esteroides y micofenolato mofetil como terapia inmunosupresora de base. Dos de los once casos de TRD en nuestra serie presentaron rechazo agudo leve que requirió el uso de ciclosporina A, dada la alta sensibilidad de la masa nefronal subóptima al uso de drogas nefrotóxicas $\left({ }^{34}\right)$. La ciclosporina A fue pospuesta e indicada sólo en casos de terapia de rescate $\left({ }^{31}\right)$.

El presente trabajo resalta la histología renal previa como método de selección del TRD $\left({ }^{16,17,29}\right)$, flexibilizando así los limites impuestos a la edad del donante.

Futuras investigaciones demostrarán si el duplicar la masa nefronal sirva para retardar o prevenir la disfunción crónica del injerto, consolidando así el trasplante renal "dos en uno" $\left.{ }^{2}\right)$ como el camino correcto para ampliar la fuente de donantes y ofrecer renovadas esperanzas a los pacientes en lista de espera.

\section{REFERENCIAS BIBLIOGRÁFICAS}

1. Light JA, Kowalski AE, Ritchie WO, Gage F, Sasaki TM, Aquino A, Callender CO. New profile of cadaveric donors: what are the kidney donor limits? Transplant Proc. 1996;28(1):17-20.

2. Dietl KH, Wolters H, Marschall B, Senninger N, Heidenreich S. Cadaveric "two-in-one" kidney transplantation from marginal donors: experience of 26 cases after 3 years. Transplantation. 2000;70(5):790-4.

3. Lu AD, Carter JT, Weinstein RJ, Stratta RJ, Taylor RJ, Bowers VD, et al. Outcome in recipients of dual kidney transplants: an analysis of the dual registry patients. Transplantation. 2000;69(2):281-5.

4. Ponticelli C. Should renal transplantation be offered to older patients? Nephrol Dial Transplant. 2000;15(3):315-7. Review.

5. Ojo AO, Hanson JA, Meier-Kriesche H, Okechukwu CN, Wolfe RA, Leichtman AB, et al. Survival in recipients of marginal cadaveric donor kidneys compared with other recipients and wait-listed transplant candidates. J Am Soc Nephrol. 2001;12(3):589-97.

6. Bunnapradist S, Gritsch HA, Peng A, Jordan SC, Cho YW. Dual kidneys from marginal adult donors as a source for cadaveric renal transplantation in the United States. J Am Soc Nephrol. 2003;14(4):1031-6.

7. Remuzzi G, Grinyo J, Ruggenenti P, Beatini M, Cole EH, Milford EL, et al. Early experience with dual kidney transplantation in adults using expanded donor criteria. Double Kidney Transplant Group (DKG). J Am Soc Nephrol. 1999;10(12):2591-8.

8. Berardinelli L, Beretta C, Raiteri M, Pasciucco A, Carini 
M. Long-term results of 211 single necrokidney transplantations from extreme-age donors: why dual allograft? Transplant Proc. 2001;33(7-8):3774-6.

9. Beckurts UT, Stippel D, Pollok M, Arns W, Weber M, Holscher AH. Single-center experience with the "Old for Old" program for renal transplantation. Transplant Proc. 2001;33(7-8):3779-80.

10. Rigotti P, Cadrobbi R, Furian L, Baldan N, Sarzo G, Liberati L, et al. Short-term outcome of dual kidney transplantation at a single center. Transplant Proc. 2001;33(7-8):3771-3.

11. Johnson LB, Kuo PC, Schweitzer EJ, Ratner LE, Klassen DK, Hoehn-Saric EW, et al. Double renal allografts successfully increase utilization of kidneys from older donors within a single organ procurement organization. Transplantation. 1996;62(11):1581-3.

12. Vivas CA, Gritsch HA, Shapiro R, Scantlebury VP, Hickey DP, Hakala TR, et al. Cadaveric renal transplantation using donors over 60 years old-5 year follow-up. Transplant Proc. 1997;29(1-2):112.

13. Hariharan S, McBride MA, Bennett LE, Cohen EP. Risk factors for renal allograft survival from older cadaver donors. Transplantation. 1997;64(12):1748-54.

14. Johnson LB, Kuo PC, Dafoe DC, Drachenberg CB, Schweitzer EJ, Alfrey EJ, et al. The use of bilateral adult renal allografts - a method to optimize function from donor kidneys with suboptimal nephron mass. Transplantation. 1996;61(8):1261-3.

15. Vásquez E, Veiga A. Biopsia de donantes renales subóptimos. Importancia de una correcta valoración. Nefrología. 2002;XXII(1):1-3(editorial).

16. Karpinski J, Lajoie G, Cattran D, Fenton S, Zaltzman J, Cardella $\mathrm{C}$, et al. Outcome of kidney transplantation from high-risk donors is determined by both structure and function. Transplantation. 1999;67(8):1162-7.

17. Pokorna E, Vitko S, Chadimova M, Schuck O, Ekberg H. Proportion of glomerulosclerosis in procurement wedge renal biopsy cannot alone discriminate for acceptance of marginal donors. Transplantation. 2000;69(1):36-43.

18. Solá R, Guirado Ll. La edad con criterio de selección de donante y receptor en un programa de trasplante renal. Act Fund Perignert. 1999;18(4).

19. Kumar MS, Panigrahi D, Dezii CM, Laskow DA, Abouna GM, Brezin J, et al. Experience with transplantation of elderly donor kidneys. Transplant Proc. 1997;29(8):3281-2.

20. Luke RG, Beck LH. Gerontologizing nephrology. J Am Soc Nephrol. 1999;10(8):1824-7.

21. Mizutani K, Yamada S, Katoh N, Ono Y, Ohshima S, Kinukawa T, et al. Cadaveric kidneys from older donors and their effective use in transplantation: a risk factor for longterm graft survival. Transplant Proc. 1997;29(1-2):113-5.

22. Ojo AO, Leichtman AB, Punch JD, Hanson JA, Dickinson $\mathrm{DM}$, Wolfe RA, et al. Impact of pre-existing donor hypertension and diabetes mellitus on cadaveric renal transplant outcomes. Am J Kidney Dis. 2000;36(1):153-9.

23. Kumar MS, Panigrahi D, Dezii CM, Abouna GM, Brezin J, Chvala R, et al. Transplantation of elderly donor kidneys into young adults. Transplant Proc. 1997;29(8):3377-8.

24. Fulladosa X, Moreso F, Narvaez JA, Grinyo JM, Seron D. Estimation of total glomerular number in stable renal transplants. J Am Soc Nephrol. 2003;14(10):2662-8.

25. Sola R, Guirado L, Lopez Navidad A, Caballero F, Agraz I, Diaz M, et al. Renal transplantation with limit donors: to what should the good results obtained be attributed? Transplantation. 1998;66(9):1159-63.

26. Carrera M, Gonzales C, Condom E, Bernat R. Biopsia del donante en el trasplante renal. Rev Esp Patol. 2002;35(3):295-300.

27. Randhawa PS, Minervini MI, Lombardero M, Duquesnoy R, Fung J, Shapiro R, et al. Biopsy of marginal donor kidneys: correlation of histologic findings with graft dysfunction. Transplantation. 2000;69(7):1352-7.

28. Sharma AK, Brown M, Connolly J, Bakran A, Ahmad R, Sells RA. Analysis of factors affecting the outcome of renal transplantation in older people. Transplant Proc. 1997;29(12):261.

29. Meier-Kriesche HU, Ojo AO, Hanson JA, Kaplan B. Exponentially increased risk of infectious death in older renal transplant recipients. Kidney Int. 2001;59(4):153943.

30. Meier-Kriesche HU, Ojo A, Hanson J, Cibrik D, Lake K, Agodoa LY, et al. Increased immunosuppressive vulnerability in elderly renal transplant recipients. Transplantation. 2000;69(5):885-9.

31. Persson NH, Omnell Persson M, Ekberg H, Kallen R, Waldner A. Renal transplantation from marginal donors: results and allocation strategies. Transplant Proc. 2001;33(78):3759-61.

32. Tarantino A, Montagnino G, Cesana B, Berardinelli L, Passerini P, Campise M, et al. Renal transplantation from older donors. Transplant Proc. 2001;33(7-8):3769-70.

33. Bonal J, Cleries M, Vela E. Transplantation versus haemodialysis in elderly patients. Renal Registry Committee. Nephrol Dial Transplant. 1997;12(2):261-4.

34. Baylis C, Corman B. The aging kidney: insights from experimental studies. J Am Soc Nephrol. 1998;9(4):699709.

Manuscrito recibido el 12 de marzo de 2005 y aceptado para publicación el 02 mayo de 2005.

Correspondencia: Dr. Pedro Méndez Chacón

Av. Los Tallanes G-34 Urb. La Capullana-Surco.

Lima 33, Perú.

Correo-e:zednem_ordep@yahoo.com 